\title{
In vitro screening as an anthelmintic discovery pipeline for Calicophoron daubneyi: nutritive media and rumen environment-based approaches
}

\author{
K. M. Huson ${ }^{1,2} \cdot$ R. M. Morphew ${ }^{1} \cdot$ A. Winters $^{1} \cdot$ A. Cookson $^{1} \cdot$ B. Hauck ${ }^{1}$ - P. M. Brophy ${ }^{1}$ (D) \\ Received: 15 September 2020 / Accepted: 19 January 2021 / Published online: 6 February 2021 \\ (C) The Author(s) 2021
}

\begin{abstract}
Paramphistomosis can lead to morbidity and mortality of ruminant livestock within tropical and sub-tropical climates. In recent decades, rumen fluke has become an emerging infection in temperate climates across Western Europe, with Calicophoron daubneyi, the primary species present. Clinical outbreaks with $C$. daubneyi larvae are reported and adults might be responsible for production losses. There is not currently a widely licensed anthelmintic product available to control C. daubneyi. In this study, three existing flukicide anthelmintics were tested for efficacy against mature $C$. daubneyi, comparing a standard in vitro culturing assay and a new more relevant rumen fluid based in vitro compound screening protocol. The new rumen based screen confirmed that oxyclozanide was active against adult $C$. daubneyi and identified activity with praziquantel. The study highlighted the downstream value of incorporating relevant in vitro screening for anthelmintic discovery pipelines.
\end{abstract}

Keywords Paramphistomosis $\cdot$ Calicophoron daubneyi $\cdot$ Anthelmintic $\cdot$ Rumen $\cdot$ Oxyclozanide $\cdot$ Praziquantel

\section{Background}

Paramphistomosis is established as a significant cause of morbidity and mortality in ruminant livestock in tropical and subtropical climates (Godara et al. 2014; Rangel-Ruiz et al. 2003). In recent decades, paramphistome parasites have become an emerging infection of ruminant livestock in temperate climates across Western Europe (Ferreras et al. 2014; Mage et al. 2002; Gordon et al. 2013; Huson et al. 2017, 2018; Amalia Naranjo-Lucena et al. 2018; Sargison et al. 2019), with Calicophoron daubneyi clearly identified as the primary species present (Gordon et al. 2013; Jones et al. 2017; Ploeger et al. 2017; Zintl et al. 2014). A number of clinical cases attributed to acute paramphistomosis have also been reported (Mason et al. 2012; Millar et al. 2012).

Section Editor: Abdul Jabbar

P. M. Brophy

pmb@aber.ac.uk

1 Institute of Biological, Environmental \& Rural Sciences (IBERS), Aberystwyth University, Aberystwyth SY23 3DA, UK

2 Present address: Agri-Food and Biosciences Institute (AFBI), Large Park, Hillsborough BT26 6DR, UK
Infection, with adult paramphistomes can cause ruminal papillae atrophy and ulceration (Fuertes et al. 2015; Rolfe et al., 1994). The adult disease has been associated with production losses such as reduced milk yield and growth rates (Foster et al. 2008; Rojo-Vázquez et al. 2012), although the influence on production is not yet confirmed (Sargison et al. 2016).

At present, no widely licensed anthelmintic product is available to control either immature or mature paramphistome infections. The oxyclozanide-containing formulation Douvistome is registered in France for the control of Paramphistomum spp. and other oxyclozanide-containing products are reportedly used off-licence to treat paramphistome infections in countries where no licenced product is available. Oxyclozanide is the only commonly available anthelmintic compound for which efficacy against both the adult and juvenile life stages of rumen fluke infections has been consistently described (Paraud et al. 2009; Rolfe and Boray 1987). However, even at therapeutic doses, oxyclozanide may cause adverse effects including softening of the faeces, increased frequency of defecation and transient inappetence in cattle (VMD 2017), and reportedly impacts on body weight gain post-treatment (Shaheen et al. 2013). The effects of oxyclozanide overdose are significant, including depression, anorexia and diarrhoea at dosages $>25 \mathrm{mg} / \mathrm{kg}$ BW in cattle and sheep (Swan 1999), and severe weight loss 
and death following doses of $>60 \mathrm{mg} / \mathrm{kg} \mathrm{BW}$ (Walley 1966). Meat and milk withdrawal periods of 13 and 4.5 days in cattle, and 14 and 7 days in sheep, respectively, must also be observed, making oxyclozanide a less than ideal choice of anthelmintic. Therefore, there is a clear need to investigate possible alternative anthelmintic and novel compound therapies.

Closantel (as closantel sodium dihydrate) has been suggested to reduce the output of rumen fluke eggs in cattle by in vivo FECRT (Arias et al. 2013). However, alternative research has demonstrated closantel to have no significant effect on reducing paramphistome egg outputs or parasite burden (Malrait et al. 2015; Rolfe and Boray 1987). Other compounds which have shown efficacy against juvenile and/or adult rumen fluke during in vitro and in vivo tests include niclosamide (Rolfe and Boray 1987), resorantel (Rolfe and Boray 1988) and bithionol sulfoxide (Prasitirat et al. 1996), but these compounds have largely been withdrawn from sale. Thus, oxyclozanide remains the only recommended compound for the control of paramphistomosis (Sanabria et al. 2014).

Specific flukicide discovery screens applied to fluke parasites in the past have typically involved screening live parasites, both adults collected from a definitive host and newly excysted juveniles obtained from infective metacercariae (Ibarra and Jenkins 1984; Pakharukova et al. 2015) in a simple nutritive media such as RPMI 1640 or DMEM, often supplemented with glucose as an energy substrate (Howe et al. 2015) and/or sera from various sources including chicken, faetal bovine and horse (McCusker et al. 2016; Wang et al. 2019). The in vitro maintenance of many parasitic helminths is problematic due to the complexity of their metabolism and inability to meet essential environmental conditions for their survival ex-host (Ahmed 2014). Parasites maintained in vitro are exposed to an environment less suited to their survival, and maintenance times are often limited as a consequence (Behnke et al. 2008). The maintenance of Fasciola hepatica juveniles in vitro over a 6-month period where development towards the adult phenotype was shown represents an example of successful optimisation for long-term studies (McCusker et al. 2016).

In consideration of rumen fluke, and the diverse rumen environment in which they reside, essentially an anaerobic fermentation chamber comprising of ingested feed material and saliva, and a rich microbial community including bacteria, fungi and protozoans, this study incorporated a more targeted in vitro screening assay for discovering compounds with activity against adult $C$. daubneyi within an environment more closely mimicking their natural niche environment. Three existing flukicide anthelmintics were tested for efficacy against adult $C$. daubneyi. The selected anthelmintics were praziquantel, oxyclozanide and closantel (as closantel sodium dihydrate). The compounds were evaluated in two different in vitro screening protocols (maintenance in a standard chemical media and maintenance in natural rumen fluid collected perimortem from cattle). Both oxyclozanide and closantel halogenated salicylanilides and act as anthelmintics by disrupting the pathway of oxidative phosphorylation in susceptible helminth species (Swan 1999). Praziquantel is believed to act by causing calcium ion influx and spasmodic muscle contraction (Vale et al. 2017) leading to paralysis of affected parasites, leaving them open to immune-mediated attack. The three compounds selected have previously been shown to have direct effects on trematode parasites, without the need for host metabolism for activation, as is the case with the flukicide triclabendazole (TCBZ), a key anthelmintic for treating fascioliasis. TCBZ is metabolised in the host liver by sulphoxidation or hydroxylation into a number of TCBZ metabolites, predominantly TCBZ sulphoxide (TCBZ-SO) and TCBZ sulphone (TCBZ- $\mathrm{SO}_{2}$ ) which are active against fasciolid parasites (Davis et al. 2020). Selecting only anthelmintics which have direct effects on their target trematode parasites was deemed important in this instance as mature rumen fluke have only a superficial attachment to the host and are, therefore, less likely to encounter metabolised forms of anthelmintics transported via the host bloodstream in significant quantities.

\section{Methods}

\section{Test concentrations for known anthelmintics}

Anthelmintic concentrations to test in both DMEM and rumen fluid maintenance conditions were selected based on the manufacturer's recommended dose rates and existing literature on effective in vitro dosages for different parasitic flatworms. This was used to make an approximation of the maximum concentration which would be generated in the bovine rumen with respect to an oral dosing at the recommended in vivo dose. 1501 was assumed to be the average volume of a bovine rumen (Frandson et al. 2003). Dose rates of approximately $15 \mathrm{mg} / \mathrm{kg}$ bodyweight have been recommended for the treatment of paramphistomosis in cattle (Rolfe and Boray 1987). However, the manufacturers of the singular oxyclozanideonly drench marketed in the UK, Zanil (MSD Animal Health), recommend a maximum dosage in cattle of $105 \mathrm{ml}$, with an oxyclozanide concentration of $34 \mathrm{mg} / \mathrm{ml}$. This equates to a maximum of $3.57 \mathrm{~g}$ of oxyclozanide per bovine and to a maximum rumen concentration of $60 \mu \mathrm{M}$ generated for the standard maximum recommended dose of $105 \mathrm{ml}$, assuming a 150-1 volume.

For closantel, the selected range of drug concentrations used was up to $75 \mu \mathrm{M}$, the same concentration as has previously been seen to be a rapidly $(<2 \mathrm{~h})$ effective dose against adult $F$. hepatica specimens in vitro, and was the highest tested dose in this previous experiment (Skuce and Fairweather 1990). Praziquantel is the frontline drug for 
treating human schistosomiasis (Chai 2013) and is currently used in veterinary medicine to control infections with tapeworms, and in tropical areas to control bovine schistosomiasis (McKellar and Jackson 2004; Olveda et al. 2016). The recommended in vivo dose for praziquantel to control schistosomiasis in cattle is $25 \mathrm{mg} / \mathrm{kg}$ (Olveda et al. 2016) which equates to a maximum potential rumen concentration of $320 \mu \mathrm{M}$ in a $600 \mathrm{~kg}$ animal (assuming a 150-1 volume). All the anthelmintics were dissolved in dimethyl sulfoxide (DMSO). The maximum final concentration of DMSO in any condition did not exceed $0.64 \% \mathrm{v} / \mathrm{v}$.

\section{DMEM in vitro screen}

Adult C. daubneyi were collected from naturally infected cattle identified in the slaughterhouse and transported directly to the laboratory in warm $39^{\circ} \mathrm{C}$ PBS. Flukes were then added to $5 \mathrm{ml}$ of DMEM media in 6-well culture plates (Corning®) Costar ${ }^{\circledR}$ cell culture plates, Sigma, UK), 1 fluke/ml. Each well contained a fixed concentration of anthelmintic or solvent control (maximum volume of DMSO added to any well), or no additional treatment. Plates were then incubated at $39^{\circ} \mathrm{C}$ and parasite motility scored $(5=$ normal activity to $0=$ no activity; Table 1, based on Behnke et al. (2008)) hourly for $6 \mathrm{~h}$. Media were then removed, $5 \mathrm{ml}$ of fresh DMEM added and fluke maintained for a further hour before a final motility score was taken. In vitro maintenance was not extended beyond $7 \mathrm{~h}$ in the DMEM screen as previous work (data not shown) had identified that all untreated/control fluke did not reliably survive in DMEM for periods longer than 7-8 h. Flukes were then snap frozen for storage at $-80^{\circ} \mathrm{C}$.

\section{Rumen fluid in vitro screen}

Rumen fluke parasites from naturally infected cattle were collected in a local abattoir. Immediately before parasite collection, approximately $40 \mathrm{ml}$ of fresh, liquid fraction rumen fluid was squeezed from the rumen contents into a $50-\mathrm{ml}$ conical centrifuge tube (Falcon ${ }^{\mathrm{TM}}$, Fisher Scientific, UK). Parasites were removed from the rumen tissue wall into centrifuge tubes using forceps (approximately 40 parasites per tube) and tubes placed into water at $39{ }^{\circ} \mathrm{C}$ in an insulated box. Fresh liquid fraction rumen fluid was collected from a freshly opened bovine rumen in the abattoir. Rumen contents were strained through muslin cloth into a pre-warmed 1.5-1 thermos flask until almost full. The flask was loosely sealed and both rumen fluid and parasites were transported directly to the laboratory.

In the laboratory, rumen fluid was poured into a large conical flask and placed in a water bath at $39{ }^{\circ} \mathrm{C}$. Fluid was continuously bubbled with nitrogen to maintain anaerobic conditions. Rumen fluid was dispensed in $1 \mathrm{ml}$ of aliquots into individual 7-ml screw top sample tubes (Fisher Scientific, UK) containing the volume of anthelmintic stock solution required to generate the correct experimental concentrations. Sample tubes also contained approx. $0.01 \mathrm{~g}$ of finely chopped grass hay as a fermentation substrate for the rumen fluid microbes. A single live rumen fluke was added to each tube and tubes flushed with nitrogen before sealing and placing in an incubator at $39^{\circ} \mathrm{C}$. Rumen fluke motility was scored (Table 1) at 2, 4, 6, 8, 12 and $24 \mathrm{~h}$. At $24 \mathrm{~h}$, the rumen fluid and rumen fluke parasites were removed and separately snap frozen for storage at $-80^{\circ} \mathrm{C}$. PCR was used to confirm selected samples as $C$. daubneyi as previously described (Gordon et al. 2013; Huson et al. 2018; Jones et al. 2017).

\section{Determination of anthelmintic uptake by parasites in vitro}

From a representative high, mid and low concentration for each of the 3 anthelmintic compounds tested, 3 adult C. daubneyi from the 5 in each group were selected randomly for each treatment group from both DMEM and rumen fluid maintenance conditions. The selected concentrations used for each anthelmintic were as follows: oxyclozanide-25, 15, $5 \mu \mathrm{M}$; praziquantel-200,100, $15 \mu \mathrm{M}$; closantel-75, 25, $5 \mu \mathrm{M}$. Anthelmintic compounds were subsequently extracted from each parasite as follows: $2 \times 0.5-\mathrm{cm}$ stainless steel beads were added to individual rumen fluke in $2-\mathrm{ml}$ microcentrifuge
Table 1 Motility scoring chart based on Behnke et al. (2008) used to evaluate fluke activity during in vitro screens. Each individual well/tube was observed for approximately $30 \mathrm{~s}$ at each time point. Where stimulus was applied, this was touching with forceps in the case of DMEM treatment, and gentle tapping of the sealed tube in the case of the rumen fluid treatment

\begin{tabular}{ll}
\hline Motility score & Description \\
\hline 5 & Normal activity, highly active 'searching' appearance to movement \\
4 & Movement as normal but reduced frequency/speed \\
3 & Slower/minimal movements, longer periods of inactivity \\
2 & Little autonomous movement and smaller range, do respond to stimulus \\
1 & Very little movement, examples such as a twitch in muscle only, only on response to stimulus \\
0 & No movement observed \\
\hline
\end{tabular}


tubes then placed in liquid nitrogen to snap freeze. Samples were bead beaten for 1 min using a Qiagen TissueLyser LT (Qiagen, UK) at full speed. These steps were repeated once more before tubes were centrifuged at $8000 \times g$ for $2 \mathrm{~min}$. Tubes were then placed in a sonicating water bath for $5 \mathrm{~min}$ and vortex mixed for $1 \mathrm{~min}$, before sonication for a further $3 \mathrm{~min}$. A total of $1.55 \mathrm{ml}$ of HPLC-grade acetonitrile was then added to each tube and samples vortex mixed for $1 \mathrm{~min}$ and sonicated for $3 \mathrm{~min}$. Samples were placed on ice between sonication and the vortex and sonication steps were repeated a total of 3 times. Samples were then centrifuged at $10,000 \times g$ for $5 \mathrm{~min}$ and the supernatant was removed to a new 2-ml microcentrifuge tube. The supernatant samples were then dried in a vacuum centrifuge. Dried pellets were resuspended in $100-\mu l$ mobile phase ( $70 \%$ methanol, HPLC grade) and centrifuged at $10,000 \times g$ to pellet any small debris before the supernatant was pipetted into $300-\mu l$ micro-vials (VWR, UK) for HPLC analysis. This protocol was adapted from those described by Alvarez et al. (2004), Moreno et al. (2014) and Alvarez et al. (2007).

All anthelmintic samples were analysed as previously reported (Davis et al. 2020) by reverse-phase HPLC with online photodiode array detection and electrospray ionisation-ion trap tandem mass spectrometry (HPLC-PDA-ESI/MS ${ }^{n}$ ). Analyses were performed on a Thermo Finnigan LC-MS system (Thermo Electron Corp, Waltham, MA, USA) comprising a Finnigan PDA Plus detector, a Finnigan LTQ linear ion trap with an ESI source and a Waters $\mathrm{C}_{18}$ Nova-Pak column $(3.9 \times 100 \mathrm{~mm}$, particle size $4 \mu \mathrm{m})$, with column oven temperature maintained at $30^{\circ} \mathrm{C}$. The PDA scan range was set to $240-400 \mathrm{~nm}$, and injection volume was typically $10 \mu \mathrm{l}$. The mobile phase consisted of water/formic acid 100:0.1 ( $v / \mathrm{v}$; solvent $\mathrm{A}$ ) and methanol/formic acid 100:0.1 (v/v; solvent $\mathrm{B})$. The column was equilibrated with $95 \%$ solvent $\mathrm{A}$ at a flow rate of $1 \mathrm{ml} \mathrm{min}^{-1}$, with $10 \%$ going to the mass spectrometer and the percentage of solvent B increased linearly to $65 \%$ over $60 \mathrm{~min}$. MS parameters were as follows: sheath gas 30 and auxiliary gas 15 (both arbitrary units), spray voltage $-4.0 \mathrm{kV}$ in negative and $4.8 \mathrm{kV}$ in positive ionisation mode, capillary temperature $320^{\circ} \mathrm{C}$, capillary voltage $-1.0 \mathrm{~V}$ and $45 \mathrm{~V}$, respectively, and tube lens voltage -68 and $110 \mathrm{~V}$, respectively.

Total peak areas were extracted from the MS data for oxyclozanide and praziquantel and from UV spectra for closantel, owing to this providing the clearest spectral profile for this compound. Data from parasite specimens from negative control treatments and rumen fluke which had been spiked with a known amount of each anthelmintic during the extraction process were used to generate standard curves, and detectable anthelmintic concentrations within each exposed experimental parasite sample were calculated. Differences in detected anthelmintic mass between the parasite maintained in either DMEM or rumen fluid were analysed for significance in PAST
(Hammer et al. 2001) using a Students $T$ test at each different anthelmintic concentration analysed by HPLC.

\section{Determination of visible damage to parasite tegument or morphology after anthelmintic exposure}

The highest anthelmintic concentration treatments of oxyclozanide and praziquantel observed to have a negative effect on parasite motility in both the DMEM and rumen fluid experiments were selected for scanning electron microscopy (SEM) analysis. Along with anthelmintic-negative solvent controls and controls preserved immediately following collection from the host, individual rumen flukes were selected at random for examination under SEM to observe if any visible changes in morphology had occurred in relation to each treatment. In brief, following parasite collection (control) or in vitro maintenance in DMEM or rumen fluid (oxyclozanide, praziquantel and solvent control specimens), three individual parasites from each selected treatment group were transferred to $1.5 \mathrm{ml}$ of fixing solution; $4{ }^{\circ} \mathrm{C} 2.5 \% \mathrm{v} / \mathrm{v}$ glutaraldehyde in $0.1 \mathrm{M}$ sodium cacodylate at $\mathrm{pH} 7.2$, in a 2-ml microcentrifuge tube, and stored at $4{ }^{\circ} \mathrm{C}$ until required. Rumen fluke specimens were then prepared for SEM as previously described (Crusco et al. 2018) before being attached to self-adhesive conductive carbon tabs on 0.5" aluminium specimen stubs (both Agar Scientific, Stanstead, UK) and gold coated for $5 \mathrm{~min}$ in a PolaronE5000 SEM coating unit. Flukes were then imaged using a Hitachi S-4700 FESEM microscope using the Ultra High-Resolution mode and an accelerating voltage of $3.0 \mathrm{kV}$, working distance $5.0 \mathrm{~mm}$ and images captured at $2560 \times 1920$ resolution.

\section{Results}

\section{Anthelmintic screens}

The three anthelmintic compounds selected to test in the DMEM and rumen fluid screening methods all showed activity against parasite motility scores when maintained in DMEM media over a 6-h period compared to the control group maintained in the same volume of DMSO as would be present in the highest concentration anthelmintic treatment, but not exposed to any drugs. In brief, after a 6-h period the rumen fluke exposed to closantel, oxyclozanide and praziquantel all had motility reduced to 0 in all 5 replicates per concentration at concentrations of $15 \mu \mathrm{M}$ and above (Fig. 1). At $15 \mu \mathrm{M}$ praziquantel specimens were reduced to a zero score consistently after 3 -h exposure in DMEM. The most efficacious anthelmintic in the screen was oxyclozanide, reducing motility scores to 0 at $1-\mu \mathrm{M}$ concentration after $5 \mathrm{~h}$. All solvent control and negative control motility scores remained at 5 throughout the experiment (data not shown). 

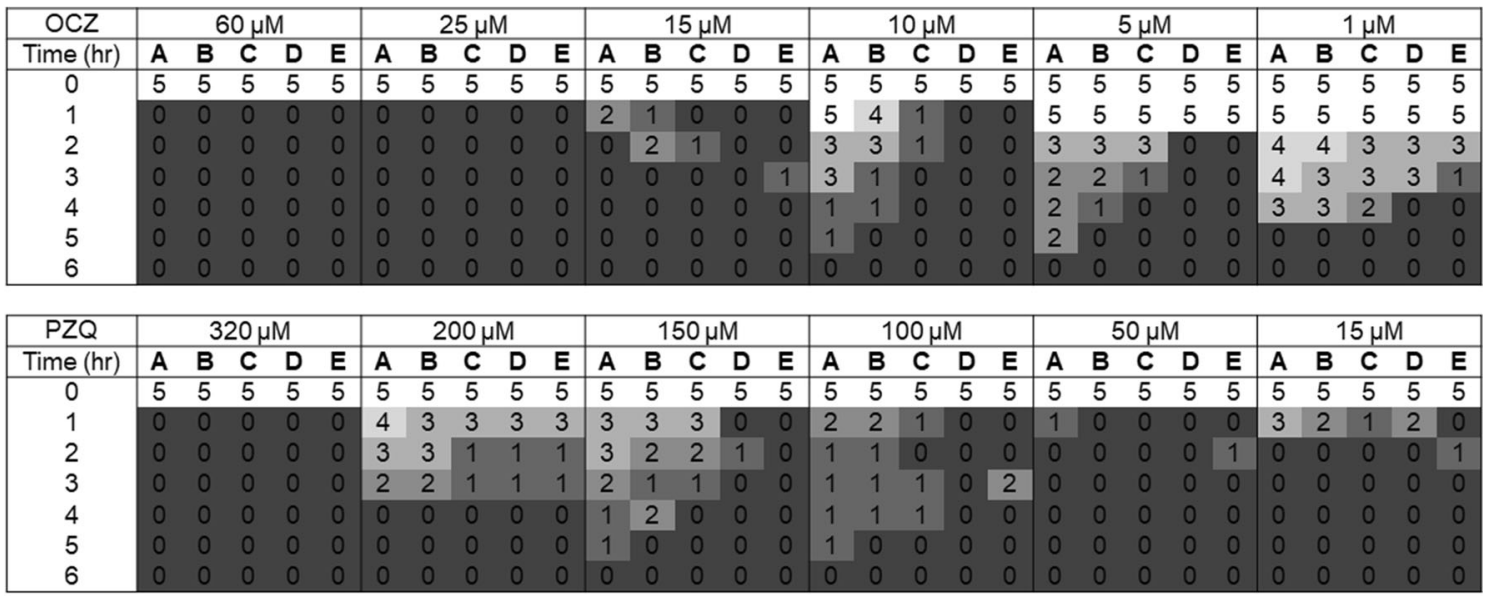

\begin{tabular}{|c|c|c|c|c|c|c|c|c|c|c|c|c|c|c|c|c|c|c|c|c|c|c|c|c|c|c|c|c|c|c|}
\hline CSD & \multicolumn{5}{|c|}{$75 \mu \mathrm{M}$} & \multicolumn{5}{|c|}{$50 \mu \mathrm{M}$} & \multicolumn{5}{|c|}{$25 \mu \mathrm{M}$} & \multicolumn{5}{|c|}{$15 \mu \mathrm{M}$} & \multicolumn{5}{|c|}{$10 \mu \mathrm{M}$} & \multicolumn{5}{|c|}{$5 \mu \mathrm{M}$} \\
\hline Time (hr) & A & B & C & D & $E$ & A & B & c & D & $E$ & A & B & $c$ & D & $E$ & A & B & $c$ & D & $E$ & A & B & C & D & $E$ & A & B & c & & $E$ \\
\hline 0 & 5 & 5 & 5 & 5 & 5 & 5 & 5 & 5 & 5 & 5 & 5 & 5 & 5 & 5 & 5 & 5 & 5 & 5 & 5 & 5 & 5 & 5 & 5 & 5 & 5 & 5 & 5 & 5 & 5 & 5 \\
\hline 1 & 4 & 3 & 3 & 0 & 1 & 0 & 0 & 0 & 0 & 0 & 2 & 2 & 3 & 2 & 1 & 4 & 3 & 2 & 1 & 1 & 4 & 2 & 2 & 2 & 2 & 5 & 5 & 5 & 4 & 3 \\
\hline 2 & 5 & 4 & 3 & 1 & 1 & 0 & 0 & 0 & 0 & 1 & 3 & 2 & 2 & 1 & 1 & 4 & 3 & 1 & 2 & 1 & 2 & 2 & 2 & 1 & 0 & 5 & 5 & 5 & 3 & 3 \\
\hline 3 & 5 & 5 & 4 & 4 & 0 & 0 & 0 & 0 & 0 & 0 & 0 & 0 & 1 & 2 & 0 & 4 & 4 & 3 & 2 & 2 & 1 & 1 & 1 & 0 & 0 & 5 & 5 & 5 & 4 & 0 \\
\hline 4 & 5 & 4 & 3 & 0 & 0 & 0 & 0 & 0 & 0 & 0 & 2 & 0 & 0 & 0 & 0 & 2 & 2 & 1 & 0 & 0 & 1 & 1 & 0 & 0 & 0 & 2 & 2 & 1 & 0 & 0 \\
\hline 5 & 0 & 0 & 0 & 0 & 0 & 1 & 0 & 0 & 0 & 0 & 1 & 1 & 1 & 0 & 0 & 2 & 1 & 1 & 0 & 0 & 1 & 0 & 0 & 0 & 0 & 0 & 0 & 0 & 0 & 0 \\
\hline 6 & 0 & 0 & 0 & 0 & 0 & 1 & 0 & 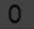 & 0 & 0 & $\checkmark$ & 0 & 0 & 0 & 0 & $\checkmark$ & 0 & 0 & 0 & u & 17 & U & 0 & 0 & u & 3 & 3 & & 0 & 0 \\
\hline
\end{tabular}

Fig. 1 Motility scores for rumen fluke maintained over a 6-h period in DMEM in oxyclozanide (OCZ), praziquantel (PZQ) and closantel (CSD). Five replicate rumen fluke were included per anthelmintic concentration, at 6 different concentrations. Control parasites were maintained in the same conditions in the presence of the highest DMSO solvent concentration needed to add each anthelmintic to the DMEM. Control parasites maintained a motility score of 5 throughout (data not shown)
In contrast, in the rumen fluid in vitro environment, closantel failed to replicate the reduction in motility to a score of 0 , as was seen in the DMEM media after $6 \mathrm{~h}$, even after the extended 24-h maintenance period (Fig. 2). Although some reduction in parasite motility was observed for all closantel treated groups in the rumen fluid screen, regardless of concentration, this reduction in motility was only observed to average scores of 2.8 on the 5-0 scale. However, oxyclozanide and

\begin{tabular}{|c|c|c|c|c|c|c|c|c|c|c|c|c|c|c|c|c|c|c|c|c|c|c|c|c|c|c|c|c|c|c|}
\hline OCZ & \multicolumn{5}{|c|}{$60 \mu \mathrm{M}$} & \multicolumn{5}{|c|}{$25 \mu \mathrm{M}$} & \multicolumn{5}{|c|}{$15 \mu \mathrm{M}$} & \multicolumn{5}{|c|}{$10 \mu \mathrm{M}$} & \multicolumn{5}{|c|}{$5 \mu \mathrm{M}$} & \multicolumn{5}{|c|}{$1 \mu \mathrm{M}$} \\
\hline Time (hr) & A & B & C & D & $E$ & A & B & C & D & $E$ & A & B & C & D & $E$ & A & B & C & D & $E$ & A & B & C & D & $E$ & A & B & C & D & $E$ \\
\hline 0 & 5 & 5 & 5 & 5 & 5 & 5 & 5 & 5 & 5 & 5 & 5 & 5 & 5 & 5 & 5 & 5 & 5 & 5 & 5 & 5 & 5 & 5 & 5 & 5 & 5 & 5 & 5 & 5 & 5 & 5 \\
\hline 2 & 0 & 0 & 0 & 0 & 0 & 2 & 1 & 0 & 1 & 0 & 2 & 3 & 1 & 1 & 2 & 4 & 3 & 3 & 1 & 2 & 5 & 5 & 3 & 5 & 4 & 5 & 5 & 5 & 5 & 5 \\
\hline 4 & 0 & 0 & 0 & 0 & 0 & 0 & 0 & 0 & 0 & 0 & 1 & 2 & 0 & 1 & 0 & 5 & 4 & 5 & 3 & 4 & 5 & 5 & 3 & 5 & 5 & 5 & 5 & 5 & 4 & 5 \\
\hline 6 & 0 & 0 & 0 & 0 & 0 & 0 & 0 & 0 & 0 & 0 & 1 & 1 & 0 & 0 & 0 & 4 & 4 & 5 & 4 & 4 & 5 & 4 & 3 & 5 & 5 & 5 & 5 & 5 & 4 & 5 \\
\hline 8 & 0 & 0 & 0 & 0 & 0 & 0 & 0 & 0 & 0 & 0 & 0 & 0 & 0 & 0 & 0 & 4 & 3 & 5 & 4 & 4 & 5 & 4 & 3 & 5 & 5 & 5 & 4 & 5 & 4 & 4 \\
\hline 12 & 0 & 0 & 0 & 0 & 0 & 0 & 0 & 0 & 0 & 0 & 0 & 0 & 0 & 0 & 0 & 3 & 4 & 5 & 3 & 4 & 4 & 5 & 3 & 4 & 5 & 4 & 5 & 5 & 3 & 4 \\
\hline 24 & 0 & 0 & 0 & 0 & 0 & 0 & 0 & 0 & 0 & 0 & 0 & 0 & 0 & 0 & 0 & 2 & 1 & 1 & 0 & 0 & 3 & 1 & 2 & 0 & 2 & 0 & 4 & 4 & 4 & 5 \\
\hline
\end{tabular}

\begin{tabular}{|c|ccccc|cccccc|cccccc|cccccc|ccccc|c|c|}
\hline PZQ & \multicolumn{4}{|c|}{$320 \mu \mathrm{M}$} & \multicolumn{4}{|c|}{$200 \mu \mathrm{M}$} & \multicolumn{4}{c|}{$150 \mu \mathrm{M}$} & \multicolumn{4}{c|}{$50 \mu \mathrm{M}$} & \multicolumn{1}{c|}{$15 \mu \mathrm{M}$} \\
\hline Time (hr) & $\mathbf{A}$ & $\mathbf{B}$ & $\mathbf{C}$ & $\mathbf{D}$ & $\mathbf{E}$ & $\mathbf{A}$ & $\mathbf{B}$ & $\mathbf{C}$ & $\mathbf{D}$ & $\mathbf{E}$ & $\mathbf{A}$ & $\mathbf{B}$ & $\mathbf{C}$ & $\mathbf{D}$ & $\mathbf{E}$ & $\mathbf{A}$ & $\mathbf{B}$ & $\mathbf{C}$ & $\mathbf{D}$ & $\mathbf{E}$ & $\mathbf{A}$ & $\mathbf{B}$ & $\mathbf{C}$ & $\mathbf{D}$ & $\mathbf{E}$ & $\mathbf{A}$ & $\mathbf{B}$ & $\mathbf{C}$ & $\mathbf{D}$ & $\mathbf{E}$ \\
\hline 0 & 5 & 5 & 5 & 5 & 5 & 5 & 5 & 5 & 5 & 5 & 5 & 5 & 5 & 5 & 5 & 5 & 5 & 5 & 5 & 5 & 5 & 5 & 5 & 5 & 5 & 5 & 5 & 5 & 5 & 5 \\
2 & 0 & 0 & 0 & 0 & 0 & 1 & 2 & 1 & 1 & 2 & 2 & 3 & 1 & 2 & 1 & 2 & 2 & 1 & 3 & 3 & 2 & 3 & 2 & 1 & 3 & 0 & 3 & 2 & 2 & 3 \\
4 & 0 & 0 & 1 & 0 & 1 & 0 & 2 & 1 & 1 & 1 & 2 & 0 & 2 & 1 & 1 & 1 & 2 & 0 & 2 & 2 & 1 & 1 & 0 & 1 & 2 & 5 & 4 & 4 & 5 & 5 \\
6 & 0 & 0 & 0 & 0 & 0 & 1 & 0 & 1 & 0 & 0 & 0 & 0 & 2 & 2 & 0 & 0 & 0 & 0 & 1 & 0 & 1 & 1 & 1 & 0 & 1 & 5 & 4 & 4 & 5 & 3 \\
8 & 0 & 0 & 0 & 0 & 0 & 0 & 2 & 1 & 1 & 0 & 0 & 1 & 1 & 0 & 0 & 0 & 0 & 1 & 1 & 0 & 1 & 0 & 1 & 0 & 1 & 5 & 4 & 5 & 5 & 2 \\
12 & 0 & 0 & 0 & 0 & 0 & 0 & 1 & 1 & 0 & 0 & 0 & 0 & 1 & 1 & 2 & 0 & 0 & 1 & 0 & 0 & 3 & 2 & 2 & 0 & 2 & 5 & 4 & 5 & 5 & 2 \\
24 & 0 & 0 & 0 & 0 & 0 & 0 & 0 & 0 & 0 & 0 & 0 & 0 & 0 & 1 & 1 & 0 & 0 & 0 & 0 & 0 & 3 & 1 & 0 & 0 & 1 & 5 & 1 & 0 & 5 & 1 \\
\hline
\end{tabular}

\begin{tabular}{|c|c|c|c|c|c|c|c|c|c|c|c|c|c|c|c|c|c|c|c|c|c|c|c|c|c|c|c|c|c|c|}
\hline CSD & \multicolumn{5}{|c|}{$75 \mu \mathrm{M}$} & \multicolumn{5}{|c|}{$50 \mu \mathrm{M}$} & \multicolumn{5}{|c|}{$25 \mu \mathrm{M}$} & \multicolumn{5}{|c|}{$15 \mu \mathrm{M}$} & \multicolumn{5}{|c|}{$10 \mu \mathrm{M}$} & \multicolumn{5}{|c|}{$5 \mu \mathrm{M}$} \\
\hline Time (hr) & A & B & C & D & $E$ & A & B & C & D & $\mathbf{E}$ & A & B & C & D & $E$ & A & B & C & D & E & A & B & C & D & $E$ & A & B & C & D & E \\
\hline 0 & 5 & 5 & 5 & 5 & 5 & 5 & 5 & 5 & 5 & 5 & 5 & 5 & 5 & 5 & 5 & 5 & 5 & 5 & 5 & 5 & 5 & 5 & 5 & 5 & 5 & 5 & 5 & 5 & 5 & 5 \\
\hline 2 & 2 & 3 & 2 & 5 & 5 & 5 & 4 & 5 & 5 & 5 & 4 & 5 & 4 & 5 & 5 & 5 & 5 & 5 & 5 & 5 & 5 & 5 & 5 & 5 & 5 & 5 & 5 & 5 & 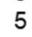 & 5 \\
\hline 4 & 5 & 5 & 5 & 5 & 5 & 5 & 4 & 5 & 5 & 5 & 4 & 5 & 5 & 5 & 5 & 5 & 4 & 5 & 4 & 5 & 5 & 5 & 5 & 5 & 0 & 5 & 5 & 5 & 5 & 4 \\
\hline 6 & 5 & 5 & 5 & 5 & 3 & 5 & 5 & 4 & 5 & 5 & 5 & 3 & 5 & 5 & 5 & 5 & 4 & 5 & 3 & 5 & 5 & 5 & 5 & 5 & 5 & 4 & 5 & 5 & 5 & 5 \\
\hline 8 & 5 & 5 & 5 & 5 & 3 & 5 & 5 & 5 & 5 & 5 & 4 & 4 & 5 & 5 & 5 & 3 & 4 & 5 & 3 & 5 & 4 & 5 & 4 & 5 & 5 & 4 & 5 & 5 & 3 & 5 \\
\hline 12 & 5 & 5 & 5 & 5 & 3 & 5 & 4 & 4 & 5 & 5 & 4 & 4 & 5 & 5 & 5 & 2 & 5 & 5 & 4 & 5 & 3 & 5 & 4 & 5 & 2 & 5 & 3 & 5 & 5 & 4 \\
\hline 24 & 4 & 4 & 5 & 3 & 2 & 4 & 4 & 3 & 4 & 3 & 4 & 2 & 1 & 4 & 4 & 2 & 5 & 5 & 4 & 1 & 0 & 5 & 3 & 4 & 2 & 1 & 3 & 4 & 5 & 4 \\
\hline
\end{tabular}

Fig. 2 Motility scores for adult rumen fluke maintained over a 24-h period in rumen fluid in oxyclozanide (OCZ), praziquantel (PZQ) and closantel (CSD). Five replicate rumen fluke were included per anthelmintic concentration, at 6 concentrations. Control parasites were maintained in the same conditions in the presence of the highest DMSO solvent concentration needed to add each anthelmintic to each rumen fluid replicate. The control parasites maintained a motility score of 5 throughout (data not shown) 
praziquantel were observed to stop all motility of the rumen fluke during the course of the 24-h period in rumen fluid. For praziquantel, an estimated concentration of $75 \mu \mathrm{M}$ or above was required to largely reduce motility scores to 0 , although not all individuals were immotile at this point. A concentration of $320 \mu \mathrm{M}$ praziquantel appeared effective, with all individuals consistently scoring 0 for motility from $6 \mathrm{~h}$ of in vitro exposure onwards. Oxyclozanide was also effective, with a $25-\mu \mathrm{M}$ concentration required to reduce motility to 0 in all 5 individual rumen fluke replicates after just $4 \mathrm{~h}$ of in vitro exposure. As with DMEM, all solvent and negative control parasite motility scores remained at 5 throughout the experiment (data not shown).

\section{Analysis of rumen fluke anthelmintic uptake during in vitro screening via HPLC-MS}

A high-pressure liquid chromatography (HLPC) assay was used to determine if the rumen fluke parasites actually internalised the anthelmintic compounds they were exposed to in vitro. To this end, three individual parasites from a low, mid and high tested concentration of each anthelmintic in both DMEM and rumen fluid screening conditions were randomly selected for extraction from the parasite somatic tissues followed by analysis with HPLC. Notably, for both closantel and praziquantel, higher anthelmintic levels were detected within the DMEM-maintained parasites than in the rumen fluid-maintained parasites, despite the 18-h difference in the in vitro maintenance time endpoints, and therefore longer period of exposure (Fig. 3). In the case of oxyclozanide, higher levels were detected in the parasites screened in rumen fluid compared to their counterparts in the same concentrations in DMEM. Anthelmintic levels extracted from the parasites generally increased with the in vitro anthelmintic concentration, although in the $75 \mu \mathrm{M}$ closantel samples from the rumen fluid screen only an average of $67.8 \mathrm{ng}$ of anthelmintic was detected, lower than the $5 \mu \mathrm{M}$ and $25 \mu \mathrm{M}$ conditions within this treatment. It is interesting to note that despite considerably longer maintenance and exposure time in rumen fluid than DMEM ( $24 \mathrm{~h}$ instead of $6 \mathrm{~h}$ ), only the oxyclozanide treated specimens had a higher level detectable in the rumen fluid screened parasites compared to the corresponding DMEM treatment. For the parasites exposed to closantel which were motile at the end of the 24-h rumen fluid screen, minimal levels of anthelmintic were detected in the somatic preparations by HPLC. Additionally, a higher concentration of praziquantel was required to see similar activity against rumen fluke in the rumen fluid in vitro conditions as opposed to in DMEM. Closantel treatments were ineffective at reducing fluke motility to 0 in rumen fluid, despite their apparent success in the DMEM screening.

Statistical analysis of the level of detectable anthelminticobserved in the DMEM and rumen fluidmaintained parasite samples did not identify significant differences between the two screening approaches, except for the comparison between the cultures containing $75 \mu \mathrm{M}$ closantel,

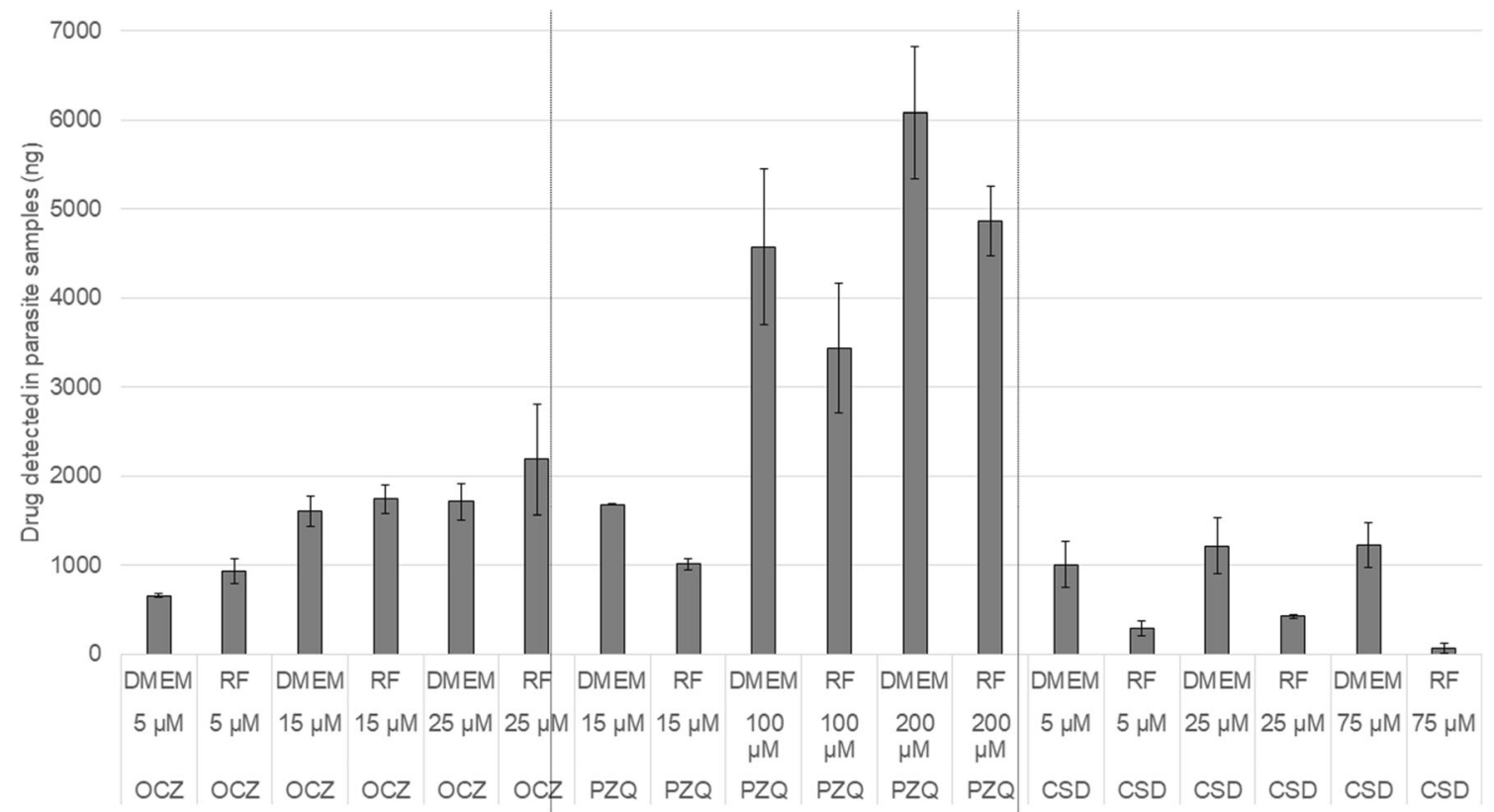

Fig. 3 Anthelmintic levels detected in parasite somatic tissues using HPLC. RF or DMEM denotes rumen fluid or DMEM screening protocol; anthelmintic concentrations are shown in micromolar, and the extracted detected anthelmintic mass shown as an average for the 3 individual parasites within each treatment group in ng. No compounds of the same mass as each tested anthelmintic could be detected in anthelmintic-negative parasite samples subjected to the same processing protocol on the HPLC platform. Error bars show the standard error of the mean for each group of replicates 
showing a significantly greater apparent anthelmintic uptake in the DMEM maintenance conditions compared to maintenance in rumen fluid $(p=0.009)$. However, it was not possible to account for the different anthelmintic exposure times in this instance. Despite a lack of statistical significance, there was a clear trend towards greater resilience of parasites exposed to praziquantel and closantel in the rumen fluid screening approach.

\section{SEM imaging of parasites following in vitro anthelmintic exposure}

To examine any morphological changes in response to anthelmintic exposure, and any differences in such effects between the DMEM and rumen fluid maintenance approaches, rumen fluke specimens were examined under SEM. Individual fluke (motility ' 0 ') from $25-\mu \mathrm{M}$ oxyclozanide and $320-\mu \mathrm{M}$ praziquantel treatments were fixed for SEM imaging. Flukes not exposed to the DMSO solvent during in vitro maintenance and specimens preserved immediately following collection from the host were also prepared for SEM as untreated controls. Images of control fluke from both DMEM and rumen fluid screening conditions showed no apparent damage or disturbance to the parasite tegument (Fig. 4a, b).

Images of fluke maintained for $6 \mathrm{~h}$ in DMEM containing $25 \mu \mathrm{M}$ oxyclozanide revealed evidence of blebbing, shedding and tearing of the upper layers of the tegument (Fig. 5a, b) along with swelling and loss of definition to the tegument grooves around the posterior and oral suckers. Specimens maintained in $25 \mu \mathrm{M}$ oxyclozanide over $24 \mathrm{~h}$ in rumen fluid were visibly in poor condition prior to SEM sample preparation. When imaging these samples on the SEM significant morphological changes could be observed with a loss of the definition of the tegumental grooves and folds compared to control samples, with also 'wrinkling' and collapse of the body structure. Moreover, apparent holes were observed in genital pore tissue, with blebbing and peeling on the tegument in the mid-region of the parasite body and swelling, loss of definition and blebbing also noted on the tegument around the posterior sucker.

The fluke maintained in $320 \mu \mathrm{M}$ praziquantel for $6 \mathrm{~h}$ in DMEM showed swelling to the tissue around the posterior sucker (Fig. 6a), as well as swelling and loss of definition in the tegument folds around the oral sucker, swelling of the
Fig. 4 SEM comparison of adult C. daubneyi maintained in $\mathrm{DMSO} / \mathrm{DMEM}$ and rumen fluid. a DMSO/DMEM 6-h DMEMmaintained rumen fluke. Top: anterior end showing oral sucker and genital pore. Mid: Grooves and folds of the mid-body tegument. Bottom: Posterior sucker used for attachment to rumen wall/papillae. b Rumen fluid 24-h maintained rumen fluke. Top: anterior end showing oral sucker and genital pore. Mid: Grooves and folds of the midbody tegument. Bottom: Posterior sucker used for attachment to rumen wall/papillae a
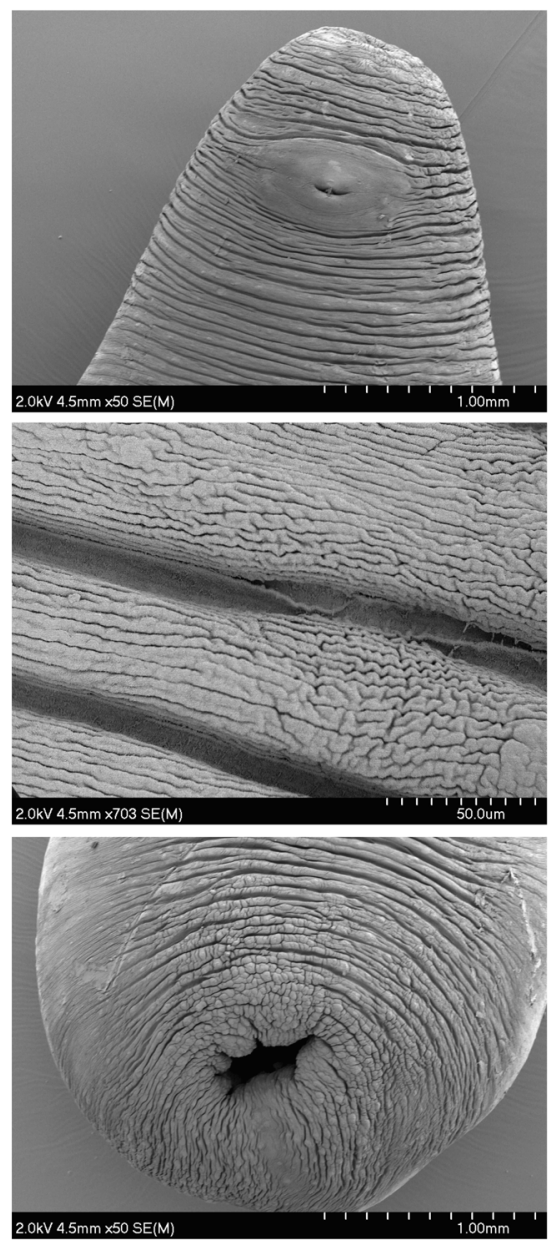

b
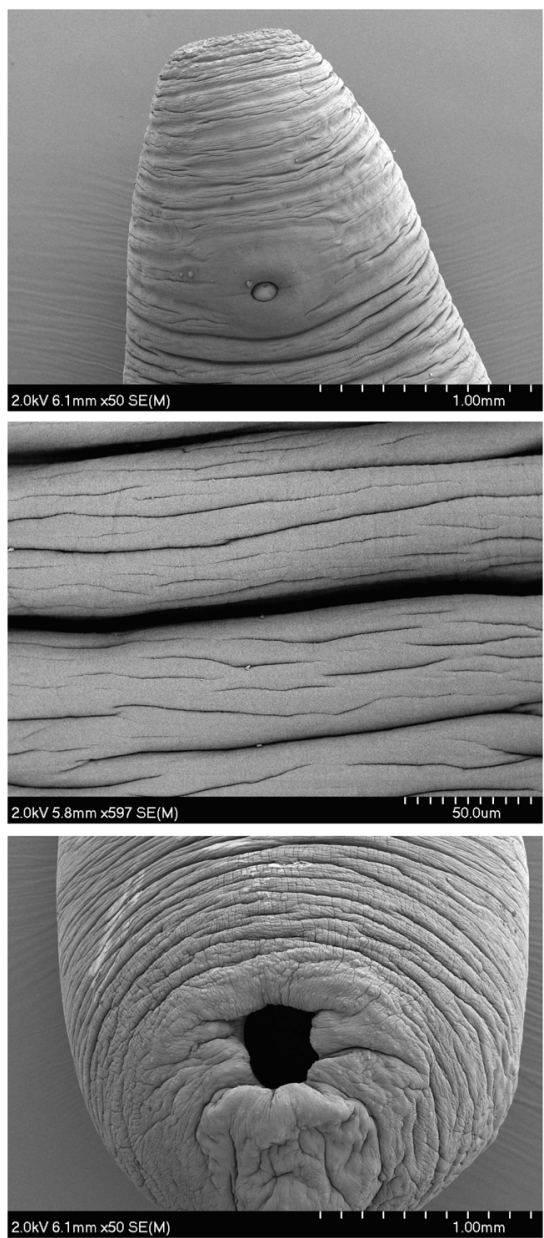
Fig. 5 SEM comparison of adult C. daubneyi maintained in DMSO/DMEM and rumen fluid in the presence of $25 \mathrm{uM}$ oxyclozanide. a Oxyclozanide, $25 \mu \mathrm{M}, 6$-h DMEM-maintained rumen fluke. Top: blebbing and shedding of the outer tegumental layers seen on the mid-body. Mid: tearing between the tegument grooves. Bottom: Swelling of the tissue of the posterior sucker. $\mathbf{b}$ Oxyclozanide, $25 \mu \mathrm{M}, 24-\mathrm{h}$ rumen fluid-maintained rumen fluke. Top: anterior end showing oral sucker and genital pore. Mid: holes visible in the tegument around the genital pore. Bottom: swelling and blebbing of the tissue at the posterior sucker a

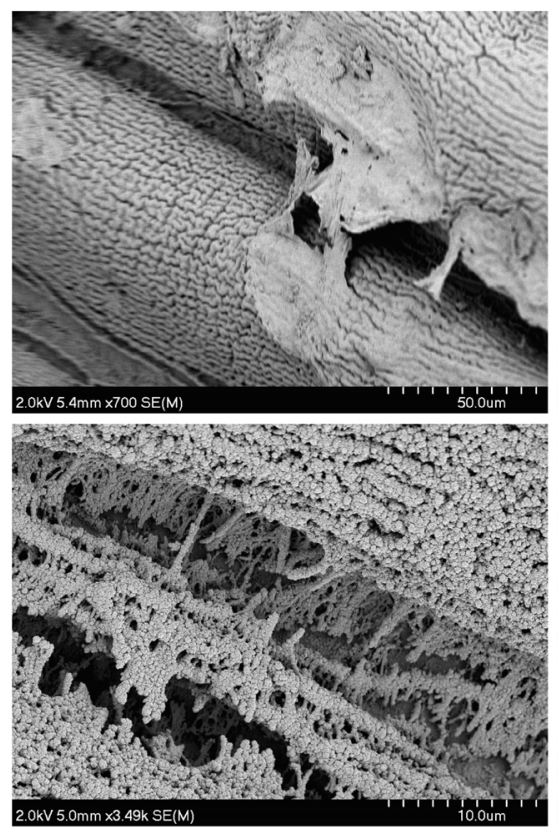

b
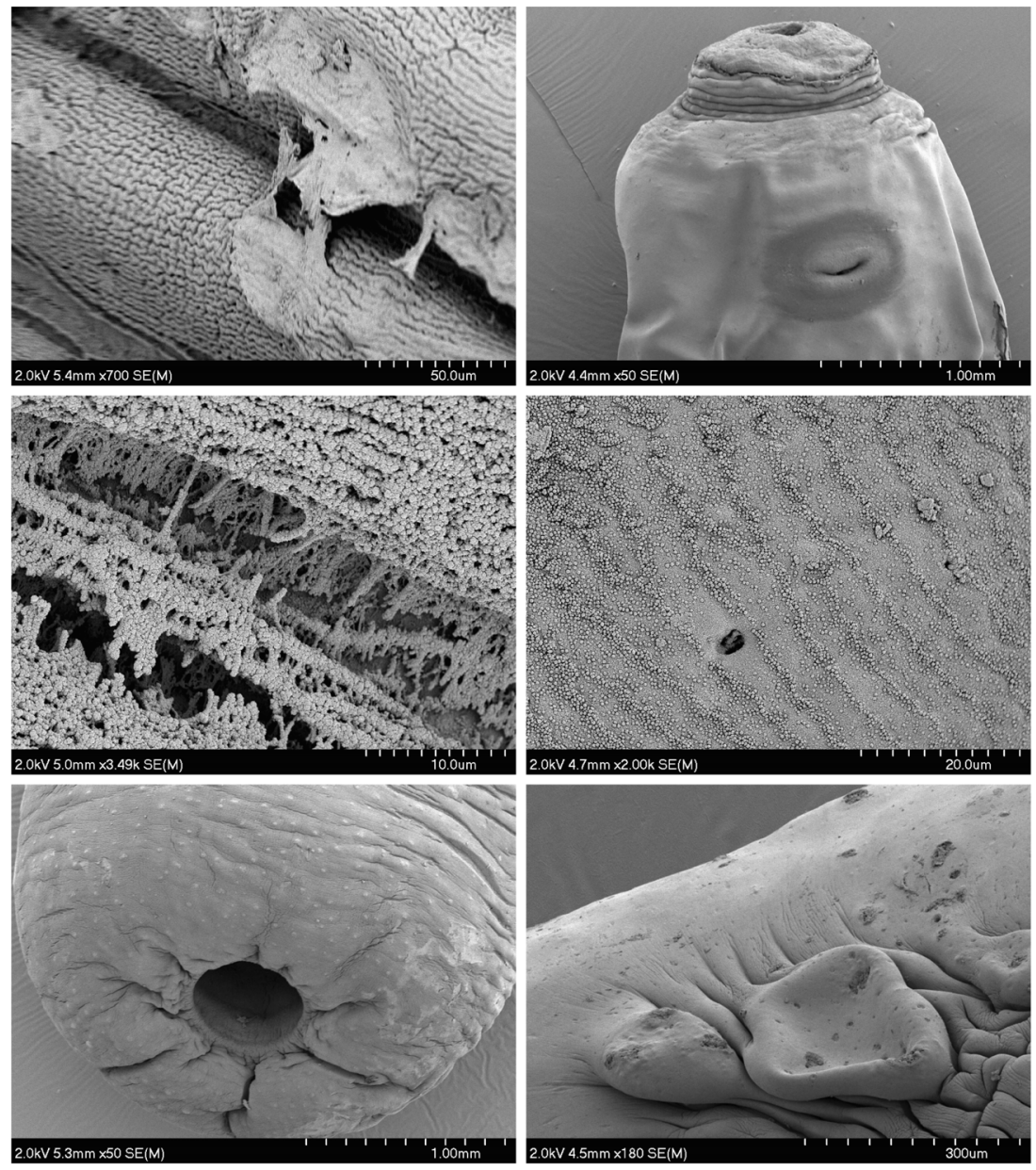

tegument in the mid-section and some tearing of the tegument starting to occur around the genital pore. In the fluke maintained for $24 \mathrm{~h}$ in rumen fluid and praziquantel at $320 \mu \mathrm{M}$ swelling of the parasite body was obvious, particularly around the posterior sucker (Fig. 6b). There was a loss of definition to the tegumental grooves and folds which can be seen on the control specimens. Several areas of tegument blebbing were seen close to the oral sucker, and tegumental tearing and cracking were observed near to the caudal sucker, along with pronounced swelling of the tissue here.

\section{Discussion}

Relevant in vitro compound screening tools are required to support control of existing and emerging pathogens. This study has identified a rumen fluid based in vitro screening tool for screening new candidates or repurposing existing compounds for adult rumen paramphistome parasites. The standard DMEM in vitro screen, an optimised system for related trematode species (Morphew et al. 2014), suggested that all three test anthelmintic compounds have potential activity against adult rumen fluke, as all were associated with a notable reduction in motility in comparison to the anthelmintic-free controls after $6 \mathrm{~h}$. However, a rumen fluid screen that better mimics the host rumen environment demonstrated that only 2 compounds, oxyclozanide and praziquantel, were active against adult rumen fluke. Indications from motility scoring at the higher tested concentrations (above $15 \mu \mathrm{M}$ for oxyclozanide and at $320 \mu \mathrm{M}$ for praziquantel) were that both these anthelmintics caused the death of these parasites in both the DMEM and rumen fluid conditions, as supported by the visible damage to the parasites, and morphological changes observed under SEM in comparison to anthelmintic-free control specimens and those preserved directly after collection from the host. The higher levels of oxyclozanide within rumen fluid-maintained fluke bodies vs their DMEM-maintained counterparts may be explained as oxyclozanide caused rapid death of the fluke in DMEM (within $1 \mathrm{~h}$ for the $25-\mu \mathrm{M}$ treatment), allowing comparatively little time for them to take up the drug, whereas in rumen fluid, it was observed that a higher concentration of oxyclozanide was required to produce the comparable effects and only parasites exposed to $>15 \mu \mathrm{M}$ drug concentrations consistently appeared dead after the $24 \mathrm{~h}$ in vitro maintenance 
Fig. 6 SEM comparison of adult C. daubneyi maintained in $\mathrm{DMSO} / \mathrm{DMEM}$ and rumen fluid in the presence of $320 \mathrm{uM}$ praziquantel. a Praziquantel,

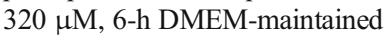
rumen fluke. Top: some tearing of the tegument around the genital pore. Mid: swelling and loss of definition in the tegument folds. Bottom: Swelling and loss of definition to the tissue around the posterior sucker. b Praziquantel, $320 \mu \mathrm{M}, 24-\mathrm{h}$ rumen fluidmaintained rumen fluke. Top and bottom: significant swelling of the parasite body at the oral and posterior suckers. Mid: cracking observed in the outer tegument near to the posterior sucker a

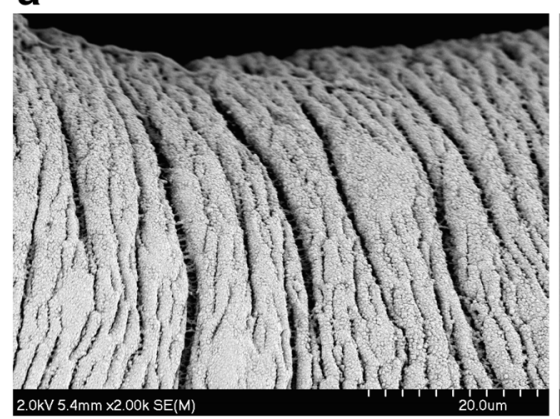

b
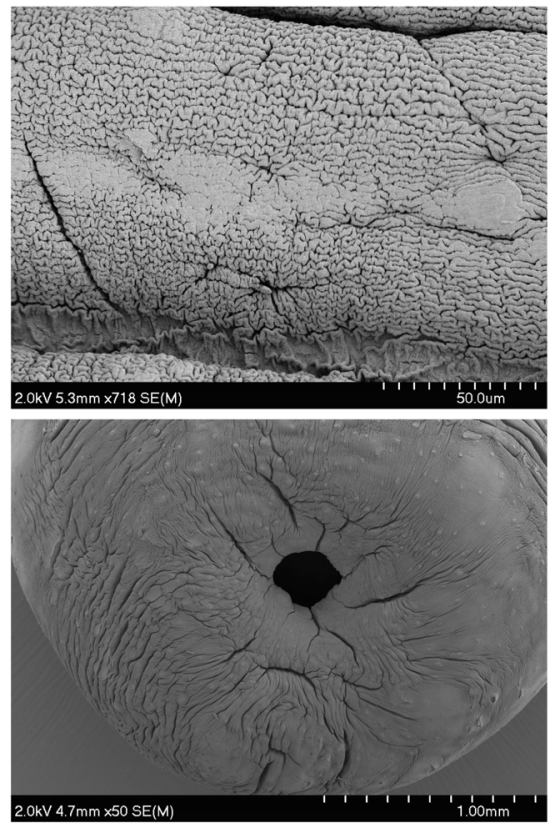
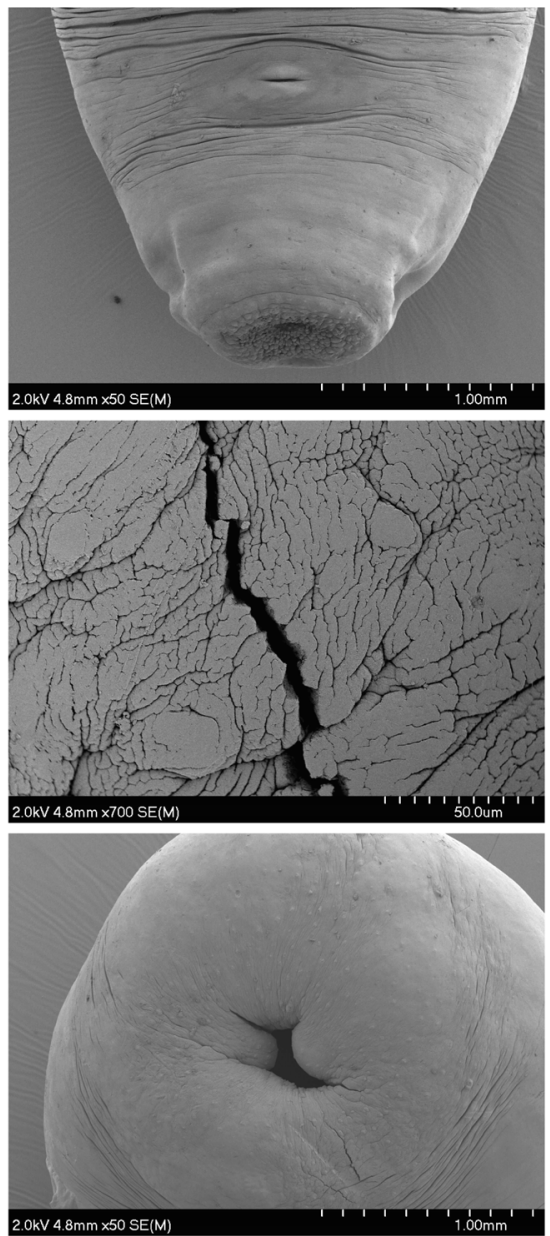

period. Alternatively, the longer exposure period in the rumen fluid treatment may have allowed greater levels of anthelmintic to passively accumulate in the parasite tissue following death, when fluke would be unable to excrete these compounds. It was not possible to determine the exact mechanism of anthelmintic accumulation in parasite tissues during this study. Higher levels of internalised anthelmintic were observed in both closanteland praziquantel-treated parasites maintained in DMEM, where it is considered that the parasites would have been under greater environmental stress, whereas the lower levels detected in the specimens maintained in rumen fluid suggests that parasites are more resilient against anthelmintic toxic effects in a more favourable environment.

Similar effects of anthelmintic compounds on rumen parasites have previously been observed using SEM. Examination of gastrointestinal parasites including rumen flukes after plant compound or anthelmintic exposure using SEM imaging has been widely used to assess signs of physical damage to the parasites caused by the compounds in question (MartínezOrtíz-de-Montellano et al. 2013; Saowakon et al. 2013). However, these previous studies have been completed using less environmentally relevant in vitro screens.
The activity of praziquantel reported here against adult C. daubneyi must currently be considered with caution. Previous in vivo studies have found no significant success of praziquantel in treating infections with other species of rumen fluke (Pakharukova et al. 2015).

Predicting in vivo activity from in vitro anthelmintic trials based on motility scoring has been deemed problematic (Behnke et al. 2008; Pakharukova et al. 2015; Saowakon et al. 2013) as motility scoring is a relatively subjective measure of death. Inactivity is often presumed to indicate parasite death although this may not necessarily be the case, particularly with praziquantel which is known to cause paralysis in other trematode and cestode parasites (Pakharukova et al. 2015). Therefore, steps should be taken to support any such assumption with other data where possible. For large parasites such as rumen fluke, staining for cell death and microscopic examination is not suitable (Pakharukova et al. 2015), and high throughput screening methods looking at phenotypic indicatiors of parasites succumbing to treatment that have been developed and applied to other helminths (Buckingham et al. 2014) are not currently available for paramphistomes. Hence, the 
decision to incorporate SEM and HPLC steps into our anthelmintic discovery pipeline.

This report highlights the importance of using relevant in vitro screens. Although the predicted calculations of 'in vivo' dosage concentrations used at this stage of discovery cannot predict factors such as the balance of solid and liquid fraction rumen contents, drug dilution due to uptake by host tissues, and any possible dilution due to uptake by rumen microbes, methods which can minimise potential 'false-positive' results (as could be indicated if the results of the DMEM screen with closantel were considered in isolation) are valuable to help direct more in-depth future studies, including in vivo trials. It was also not possible to account for the effect of digesta flow and dilution rate on compounds moving out of the rumen or the effect of individual animal variation due to age, breed, etc. on the composition of rumen fluid during this in vitro screen, although it was ensured that all treatments used the same pooled rumen fluid source to remove such variability within this experiment. As with all in vitro work, further validation of any conclusions should be conducted during in vivo trials where possible and appropriate. Effective concentrations observed in vitro are frequently not comparable to effective doses identified in vitro (Githiori et al. 2006), highlighting the need to extend results from in vitro work with confirmation of efficacy and required dose through follow-up in vivo experiments.

There are previous positive reports of closantel efficacy against rumen fluke, with a reduction in FEC scores reported in cattle (Arias et al. 2013), although a separate study in sheep did not identify any efficacy of closantel for treating paramphistome infections (García-Dios et al. 2020). This is supported by our in vitro findings, wherein a more favourable rumen fluid environment closantel was not found to show significant activity against adult $C$. daubneyi and was not associated with apparent parasite death over a 24-h period in concentrations up to $75 \mu \mathrm{M}$.

The work described here clearly highlights the relevance of the rumen fluid as a medium for performing in vitro screens with adult $C$. daubneyi in addition to alternative species of rumen fluke. From the current work, DMEM, or likely equivalents, are not appropriate and have the potential to indicate false-positive compound efficacy. This is likely to apply to other simple media which are not optimised for supporting rumen fluke in vitro. The approach described using liquid fraction rumen fluid could easily be adapted to the screening of other paramphistome parasites in tropical areas where there is an urgent need for the identification of suitable anthelmintic products due to the significant morbidity and mortality associated with paramphistomosis locally (Shaheen et al. 2013).

Funding Open Access funding provided by Aberystwyth University. This work was financially supported by Aberystwyth University.
Data availability Available.

Materials availability Available.

\section{Declarations}

Ethics approval and consent to participate Not applicable (natural parasite samples from abattoir). Consent to participate is not applicable.

\section{Consent for publication Not applicable.}

Competing interests The authors declare no competing interests.

Open Access This article is licensed under a Creative Commons Attribution 4.0 International License, which permits use, sharing, adaptation, distribution and reproduction in any medium or format, as long as you give appropriate credit to the original author(s) and the source, provide a link to the Creative Commons licence, and indicate if changes were made. The images or other third party material in this article are included in the article's Creative Commons licence, unless indicated otherwise in a credit line to the material. If material is not included in the article's Creative Commons licence and your intended use is not permitted by statutory regulation or exceeds the permitted use, you will need to obtain permission directly from the copyright holder. To view a copy of this licence, visit http://creativecommons.org/licenses/by/4.0/.

\section{References}

Ahmed NH (2014) Cultivation of parasites. Trop Parasitol 4:80-89. https://doi.org/10.4103/2229-5070.138534

Alvarez LI, Mottier ML, Lanusse CE (2004) Comparative assessment of the access of albendazole, fenbendazole and triclabendazole to Fasciola hepatica: effect of bile in the incubation medium. Parasitology 128:73-81. https://doi.org/10.1017/ S0031182003004281

Alvarez LI, Mottier ML, Lanusse CE (2007) Drug transfer into target helminth parasites. Trends Parasitol 23:97-104. https://doi.org/10. 1016/j.pt.2007.01.003

Arias MSS, Sanchís J, Francisco I, Francisco R, Piñeiro P, CazapalMonteiro C, Cortiñas FJJ, Suárez JLL, Sánchez-Andrade R, PazSilva A (2013) The efficacy of four anthelmintics against Calicophoron daubneyi in naturally infected dairy cattle. Vet Parasitol 197:126-129. https://doi.org/10.1016/j.vetpar.2013.06. 011

Behnke JM, Buttle DJ, Stepek G, Lowe A, Duce IR (2008) Developing novel anthelmintics from plant cysteine proteinases. Parasit Vectors 1:29. https://doi.org/10.1186/1756-3305-1-29

Buckingham SD, Partridge FA, Sattelle DB (2014) Automated, highthroughput, motility analysis in Caenorhabditis elegans and parasitic nematodes: applications in the search for new anthelmintics. Int $\mathrm{J}$ Parasitol Drugs Drug Resist 4:226-232. https://doi.org/10.1016/j. ijpddr.2014.10.004

Chai JY (2013) Praziquantel treatment in trematode and cestode infections: an update. Infect Chemother 45:32-43. https://doi.org/10. 3947/ic.2013.45.1.32

Crusco A, Bordoni C, Chakroborty A, Whatley KCL, Whiteland H, Westwell AD, Hoffmann KF (2018) Design, synthesis and anthelmintic activity of 7-keto-sempervirol analogues. Eur J Med Chem 152:87-100. https://doi.org/10.1016/j.ejmech.2018.04.032

Davis CN, Winters A, Milic I, Devitt A, Cookson A, Brophy PM, Morphew RM (2020) Evidence of sequestration of triclabendazole 
and associated metabolites by extracellular vesicles of Fasciola hepatica. Sci Rep 10:1-11. https://doi.org/10.1038/s41598-02069970-4

Ferreras MC, González-Lanza C, Pérez V, Fuertes M, Benavides J, Mezo M, González-Warleta M, Giráldez J, Martínez-Ibeas AM, Delgado L, Fernández M, Manga-González MY (2014) Calicophoron daubneyi (Paramphistomidae) in slaughtered cattle in Castilla y León (Spain). Vet Parasitol 199:268-271. https://doi.org/10.1016/ j.vetpar.2013.10.019

Foster AP, Otter A, O'Sullivan T, Cranwell MP, Twomey DF, Millar MF, Taylor MA (2008) Rumen fluke (paramphistomosis) in British cattle. Vet Rec 162:528-528. https://doi.org/10.1136/vr. 162.16.528-a

Frandson RD, Fails AD, Wilke WL (2003) Anatomy and physiology of farm animals, 6th edn. Blackwell Publishing Ltd, Oxford

Fuertes M, Pérez V, Benavides J, González-Lanza MC, Mezo M, González-Warleta M, Giráldez FJ, Fernández M, Manga-González MY, Ferreras MC (2015) Pathological changes in cattle naturally infected by Calicophoron daubneyi adult flukes. Vet Parasitol 209: 188-196. https://doi.org/10.1016/j.vetpar.2015.02.034

García-Dios D, Díaz P, Viña M, Remesar S, Prieto A, López-Lorenzo G, Cao JMD, Panadero R, Díez-Baños P, López CM (2020) Efficacy of oxyclozanide and closantel against rumen flukes (paramphistomidae) in naturally infected sheep. Animals 10:1-9. https://doi.org/10.3390/ani10111943

Githiori JB, Athanasiadou S, Thamsborg SM (2006) Use of plants in novel approaches for control of gastrointestinal helminths in livestock with emphasis on small ruminants. Vet Parasitol 139:308320. https://doi.org/10.1016/j.vetpar.2006.04.021

Godara R, Katoch R, Yadav A, Rastogi A (2014) Epidemiology of paramphistomosis in sheep and goats in Jammu. India J Parasit Dis 38:423-428. https://doi.org/10.1007/s12639-013-0264-y

Gordon DK, Roberts LCP, Lean N, Zadoks RN, Sargison ND, Skuce PJ (2013) Identification of the rumen fluke, Calicophoron daubneyi, in GB livestock: possible implications for liver fluke diagnosis. Vet Parasitol 195:65-71. https://doi.org/10.1016/j.vetpar.2013.01.014

Hammer Ø, Harper DAT, Ryan PD (2001) PAST: paleontological statistics software package for education and data analysis. Palaeontol Electron 4(1):1-9. https://doi.org/10.1016/j.bcp.2008.05.025

Howe S, Zophel D, Subbaraman H, Unger C, Held J, Engleitner T, Hoffmann WH, Kreidenweissa A (2015) Lactate as a novel quantitative measure of viability in Schistosoma mansoni drug sensitivity assays. Antimicrob Agents Chemother 59:1193-1199. https://doi. org/10.1128/AAC.03809-14

Huson KM, Oliver NAM, Robinson MW (2017) Paramphistomosis of ruminants: an emerging parasitic disease in Europe. Trends Parasitol xx 33:1-9. https://doi.org/10.1016/j.pt.2017.07.002

Huson KM, Morphew RM, Allen NR, Hegarty MJ, Worgan HJ, Girdwood SE, Jones EL, Phillips HC, Vickers M, Swain M, Smith D, Kingston-smith AH, Brophy PM (2018) Polyomic tools for an emerging livestock parasite, the rumen fluke Calicophoron daubneyi; identifying shifts in rumen functionality. Parasit Vectors:1-22

Ibarra OF, Jenkins DC (1984) An in vitro screen for new fasciolicidal agents. Z Parasitenkd 70:655-661. https://doi.org/10.1007/ BF00926594

Jones RA, Brophy PM, Mitchell ES, Williams HW (2017) Rumen fluke (Calicophoron daubneyi) on Welsh farms: prevalence, risk factors and observations on co-infection with Fasciola hepatica. Parasitology 144:237-247. https://doi.org/10.1017/ S0031182016001797

Mage C, Bourgne H, Toullieu J-M, Rondelaud D, Dreyfuss G (2002) Fasciola hepatica and Paramphistomum daubneyi: changes in prevalences of natural infections in cattle and in Lymnaea truncatula from Central France over the past 12 years. Vet Res 33:439-447
Malrait K, Verschave S, Skuce P, Van Loo H, Vercruysse J, Charlier J (2015) Novel insights into the pathogenic importance, diagnosis and treatment of the rumen fluke (Calicophoron daubneyi) in cattle. Vet Parasitol 207:134-139. https://doi.org/10.1016/j.vetpar.2014.10. 033

Martínez-Ortíz-de-Montellano C, Arroyo-López C, Fourquaux I, TorresAcosta JFJ, Sandoval-Castro CA, Hoste H (2013) Scanning electron microscopy of Haemonchus contortus exposed to tannin-rich plants under in vivo and in vitro conditions. Exp Parasitol 133:281-286. https://doi.org/10.1016/j.exppara.2012.11.024

Mason C, Stevenson H, Cox A, Dick I (2012) Disease associated with immature paramphistome infection in sheep. Vet. Rec. 170:343344. https://doi.org/10.1136/vr.e2368

McCusker P, McVeigh P, Rathinasamy V, Toet H, McCammick E, O'Connor A, Marks NJ, Mousley A, Brennan GP, Halton DW, Spithill TW, Maule AG (2016) Stimulating neoblast-like cell proliferation in juvenile Fasciola hepatica supports growth and progression towards the adult phenotype in vitro. PLoS Negl Trop Dis 10: 1-26. https://doi.org/10.1371/journal.pntd.0004994

McKellar QA, Jackson F (2004) Veterinary anthelmintics: old and new. Trends Parasitol 20:456-461. https://doi.org/10.1016/j.pt.2004.08. 002

Millar M, Colloff A, Scholes S (2012) Disease associated with immature paramphistome infection. Vet. Rec. 171:509-510. https://doi.org/ 10.1136/vr.e7738

Moreno L, Ceballos L, Fairweather I, Lanusse C, Alvarez L (2014) Timecourse and accumulation of triclabendazole and its metabolites in bile, liver tissues and flukes collected from treated sheep. Exp Parasitol 136:14-19. https://doi.org/10.1016/j.exppara.2013.10.014

Morphew RM, MacKintosh N, Hart EH, Prescott M, LaCourse EJ, Brophy PM (2014) In vitro biomarker discovery in the parasitic flatworm Fasciola hepatica for monitoring chemotherapeutic treatment. EuPA Open Proteomics 3:85-99. https://doi.org/10.1016/j. euprot.2014.02.013

Naranjo-Lucena A, Munita Corbalán MP, Martínez-Ibeas AM, McGrath G, Murray G, Casey M, Good B, Sayers R, Mulcahy G, Zintz A (2018) Spatial patterns of Fasciola hepatica and Calicophoron daubneyi infections in ruminants in Ireland and modelling of $\mathrm{C}$. daubneyi infection. Parasites Vectors 11:531. https://doi.org/10. 1186/s13071-018-3114-z

Olveda RM, Tallo V, Olveda DU, Inobaya MT, Chau TN, Ross AG (2016) National survey data for zoonotic schistosomiasis in the Philippines grossly underestimates the true burden of disease within endemic zones: implications for future control. Int $\mathrm{J}$ Infect Dis 45: 13-17. https://doi.org/10.1016/j.ijid.2016.01.011

Pakharukova MY, Shilov AG, Pirozhkova DS, Katokhin AV, Mordvinov VA (2015) The first comprehensive study of praziquantel effects in vivo and in vitro on European liver fluke Opisthorchis felineus (Trematoda). Int J Antimicrob Agents 46:94-100. https://doi.org/10. 1016/j.ijantimicag.2015.02.012

Paraud C, Gaudin C, Pors I, Chartier C (2009) Efficacy of oxyclozanide against the rumen fluke Calicophoron daubneyi in experimentally infected goats. Vet J 180:265-267. https://doi.org/10.1016/j.tvj1. 2008.01.002

Ploeger HW, Ankum L, Moll L, van Doorn DCK, Mitchell G, Skuce PJ, Zadoks RN, Holzhauer M (2017) Presence and species identity of rumen flukes in cattle and sheep in the Netherlands. Vet Parasitol 243:42-46. https://doi.org/10.1016/j.vetpar.2017.06.009

Prasitirat P, Nithiuthai S, Ruengsuk K (1996) Efficacy of bithionol sulfoxide, niclosamide and fenbendazole against natural rumen fluke infections in cattle. 34. Kasetsart Univ. Annual Conference, Bangkok

Rangel-Ruiz LJ, Albores-Brahms ST, Gamboa-Aguilar J (2003) Seasonal trends of Paramphistomum cervi in Tabasco. Mexico Vet Parasitol 116:217-222. https://doi.org/10.1016/j.vetpar.2003.07.002 
Rojo-Vázquez FA, Meana A, Valcárcel F, Martínez-Valladares M (2012) Update on trematode infections in sheep. Vet Parasitol 189:15-38. https://doi.org/10.1016/j.vetpar.2012.03.029

Rolfe PF, Boray JC (1987) Chemotherapy of paramphistomosis in cattle. Aust Vet J 64:328-332. https://doi.org/10.1111/j.1751-0813.1987. tb06060.x

Rolfe PF, Boray JC (1988) Chemotherapy of paramphistornosis in sheep. Aust Vet J 65:148-150. https://doi.org/10.1111/j.1751-0813.1988. tb14443.x

Rolfe PF, Boray JC, Collins GH (1994) Pathology of infection with Paramphistomum ichikawai in sheep. Int J Parasitol 24:995-1004. https://doi.org/10.1016/0020-7519(94)90165-1

Sanabria R, Moreno L, Alvarez L, Lanusse C, Romero J (2014) Efficacy of oxyclozanide against adult Paramphistomum leydeni in naturally infected sheep. Vet Parasitol 206((3-4)):277-281. https://doi.org/10. 1016/j.vetpar.2014.09.022

Saowakon N, Lorsuwannarat N, Changklungmoa N, Wanichanon C, Sobhon P (2013) Paramphistomum cervi: the in vitro effect of plumbagin on motility, survival and tegument structure. Exp Parasitol 133:179-186. https://doi.org/10.1016/j.exppara.2012.11. 018

Sargison N, Francis E, Davison C, Bronsvoort BM de C, Handel I, Mazeri S (2016) Observations on the biology, epidemiology and economic relevance of rumen flukes (Paramphistomidae) in cattle kept in a temperate environment. Vet Parasitol 219:7-16

Sargison ND, Shahzad K, Mazeri S, Chaudhry U (2019) A high throughput deep amplicon sequencing method to show the emergence and spread of Calicophoron daubneyi rumen fluke infection in United Kingdom cattle herds. Vet Parasitol 268:9-15. https://doi.org/10. 1016/j.vetpar.2019.02.007

Shaheen H, Sadek KM, Bazh EK (2013) Evaluation of oxyclozanide and niclosamide combination as alternative antiparamphistomal therapy in buffaloes. African J Pharm Pharmacol 7:2157-2166. https://doi. org/10.5897/AJPP2013.3493

Skuce PJ, Fairweather I (1990) The effect of the hydrogen ionophore closantel upon the pharmacology and ultrastructure of the adult liver fluke Fasciola hepatica. Parasitol Res 76:241-250. https://doi.org/ 10.1007/BF00930821

Swan GE (1999) The pharmacology of halogenated salicylanilides and their anthelmintic use in animals. J S Afr Vet Assoc 70:61-70. https://doi.org/10.4102/jsava.v70i2.756

Vale N, Gouveia MJ, Rinaldi G, Brindley PJ, Gärtner F, Da Costa JMC (2017) Praziquantel for schistosomiasis: single-drug metabolism revisited, mode of action, and resistance. Antimicrob Agents Chemother 61. https://doi.org/10.1128/AAC.02582-16

VMD, 2017. Summary of product characteristics: Zanil Fluke Drench 34 $\mathrm{mg} / \mathrm{ml}$ Oral Suspension [WWW Document]. Vet. Med. Dir. URL https://www.vmd.defra.gov.uk/ProductInformationDatabase/ Default.aspx. Accessed 6 Dec 2020

Walley JK (1966) Oxyclozanide (3,3', 5,5', 6-pentachloro-2.2'dihydroxybenzanil-ide-'ZamT) in the treatment of the liver fluke Fasciola hepatica in sheep and cattle. Vet. Rec. 78:267-276

Wang J, Chen R, Collins JJ III (2019) Systematically improved in vitro culture conditions reveal new insights into the reproductive biology of the human parasite Schistosoma mansoni. PLoS Biol 17: e3000254

Zintl A, Garcia-Campos A, Trudgett A, Chryssafidis AL, Talavera-Arce S, Fu Y, Egan S, Lawlor A, Negredo C, Brennan G, Hanna RE, De Waal T, Mulcahy G (2014) Bovine paramphistomes in Ireland. Vet Parasitol 204:199-208. https://doi.org/10.1016/j.vetpar.2014.05. 024

Publisher's note Springer Nature remains neutral with regard to jurisdictional claims in published maps and institutional affiliations. 